\title{
COMPLIANCE NO CONTEXTO DE INOVAÇÃO: UMA REVISÃO DA LITERATURA INTERNACIONAL
}

Isaac Danon Junior ${ }^{1}$; Camila de Sousa Pereira Guizzo1; Tarso Barreto Rodrigues Nogueira ${ }^{1}$

1SENAI CIMATEC, Av. Orlando Gomes, n¹845, Salvador/BA; e-mail: contabeisbacharelado@yahoo.com.br

Resumo: Pretende-se analisar neste estudo como a função de compliance interfere no âmbito das empresas privadas, nas ações relacionadas à inovação, identificando ainda possíveis lacunas no campo da pesquisa. Para alcance do objetivo proposto, foram realizadas buscas no repositório Web of Science. Os principais resultados indicam a escassez de publicações e a relevância da pesquisa nessa temática como contribuição para sociedade acadêmica e empresarial.

Palavras-Chave: Compliance; Governança; Inovação; Sustentabilidade.

\section{COMPLIANCE IN INNOVATION CONTEXT: A REVIEW OF INTERNATIONAL LITERATURE}

\begin{abstract}
It is intended to analyze in this study how the compliance function interferes in the ambit of the private companies, in the actions related to the innovation, identifying also possible gaps in the research field. To reach the proposed objective, searches were performed in the Web of Science repository. The main results indicate the scarcity of publications and the relevance of research on this theme as a contribution to academic and business society.
\end{abstract}

Keywords: Compliance; Governance; Innovation; Sustainability. 


\section{INTRODUÇÃO}

O termo compliance tem sua origem no verbo to comply, que significa fazer cumprir, e pode ser entendido como "estar conforme" ou de acordo com uma norma, um regimento, um regulamento interno, ou uma deliberação do dirigente etc. O termo surgiu da preocupação das empresas norte-americanas, principalmente dos ramos farmacêutico e bancário, com algumas diretrizes instituídas pelo governo, ainda no início do século XX. Sendo assim pode-se concluir que o compliance não é algo novo, porém essa temática encontra-se em evidência, diante da situação atual de tantas notícias de corrupção que o mundo vem passando [1,2].

Deste modo, a luz do contexto histórico o autor relata que, em 1970, foram instituídas outras normas com o objetivo de evitar e punir a prática de suborno no comércio internacional. E só desse período em diante, as empresas que quisessem expandir a sua atuação teriam que se enquadrar a essas leis. Dai surge a necessidade e/ou oportunidade de implantação de departamentos e de sistematização de programas de compliance [2].

Foi observado que os conceitos de compliance e de inovação são atrelados, geralmente para alcançar o objetivo organizacional de crescimento sustentável. Para os autores, a sustentabilidade é abordada no contexto amplamente definido, ou seja, baseia-se na capacidade de uma organização equilibrar as necessidades de curto e longo prazo das partes interessadas [3].

Por outro lado, no cenário brasileiro, a relevância de se implementar uma estrutura sistematizada de conformidade (programa de compliance) se deu a partir da Lei Federal $n^{\circ} 12.846 / 2013$ e a questão de responsabilização objetiva das empresas por atos de terceiros, de dirigentes, de empregados e todo tipo de representante que atue como representante ou tenha benefícios.

A governança corporativa pode envolver atividades como a tomada de decisões e implantação de recursos para proteger e equilibrar os interesses da organização. Na prática, a avaliação das relações entre compliance, governança, riscos e gestão da inovação geralmente não é feita [2].

Cabe registrar que falar de conformidade no cenário brasileiro ainda é algo muito sensível, pois na linha do tempo o compliance começou a ser adotado no final dos anos 90 e início dos anos 2000, com modelos importados de empresas estrangeiras. E por esse motivo relevante, existe aí um processo crucial de aculturamento tanto das empresas quanto dos empregados nos tempos atuais [4].

A temática compliance é um dos assuntos que mais esteve em evidência no mundo corporativo, recentemente, e não pode ser trabalhado como um conjunto de atividades estanques ou próprias de um setor especifico da empresa. Pelo contrário, deve estar alinhado aos objetivos estratégicos e integrado aos Sistemas de Gestão da empresa. Quando trazemos os holofotes para o setor de empresas privadas essa sistemática pode ser vista em alguns casos específicos como um fator inibidor para inovação ou até mesmo bloqueador no âmbito comercial em detrimentos do grau de cumprimento e exigências legais e normativas [5]. 
Ainda neste contexto os autores trazem nos seus comentários que os imperativos de conformidade, leia-se imperativos de compliance sejam eles regulamentações externas ou dentro dos objetivos das organizações, ou ambos, conhecimentos relacionados à inovação podem se tornar uma fonte fértil de inovação organizacional. Neste entendimento comentam:

[...] as atividades de compliance, governança, riscos e inovação e podem estar diretamente ligadas à solidificação dessa estrutura orientada para o crescimento com a finalidade de alcançar vantagem competitiva. Com base nesta proposição, Compliance - inovação é definida como os processos pelos quais as bases de conhecimento do GRC (Governança, risco e Compliance) e domínios de inovação são integrados para impulsionar a sustentabilidade e exploração comercial através de processos de tomada de decisão [3].

A sistematização de conformidade (compliance) como requisito de boa prática de mercado e como exigências por parte de parceiros comerciais são fatores preponderantes que favorecem essas empresas privadas aderir a implantação do programa. Porém, acima de tudo, é incontestável o valor agregado de uma organização que consegue instituí-lo [3,5].

Outro ponto relevante a mencionar é a questão do risco que empresas privadas podem estar sujeitas, quando da relação com parceiros comerciais e fornecedores, ou seja, risco de envolverem-se em situações de fraudes, ilicitudes etc., sem contar com a possibilidade da empresa ser arrolada em investigações e para tanto faz-se necessário conhecer e entender os tipos riscos de compliance que a empresa está exposta para mitigá-los, pois estes riscos podem impactar consideravelmente a sua reputação, imagem ou até mesmo a sua sustentabilidade no mercado [6].

Dito isso, registre-se que qualquer ato e/ou conduta não ética em todas às áreas da empresa pode sim contribuir para a lista de riscos de compliance a exemplificar e relacionados abaixo: corrupção ativa e passiva; assédio moral; assédio sexual; fraudes; desvio e lavagem de dinheiro; favorecimento em processos licitatórios; cultura organizacional; evasão fiscal: venda sem documentação fiscal; ausência de recolhimento de taxas/encargos trabalhistas; não pagar empregados "por fora" ou sem o contrato formal; não nomear empregados para cargos de gestão apenas por empatia, sem atentar aos requisitos técnicos para a função previstos no plano de cargos e salários da empresa; não se pôr em situação de conflitos de interesses; riscos de imagem etc.

O compliance dentro de cada negócio fornece suporte para sustentabilidade e gestão de riscos. Para o autor, quanto maior a empresa, as metas e as conquistas, maior a existência de prováveis riscos. Dai conclui com a seguinte explanação:

[...] um complexo ecossistema tecnológico demanda contínua inovação em conformidade um amplo regramento, que envolve, entre outras coisas, investimento em segurança e privacidade de dados. Ao contrário do pensamento tradicional industrial, compliance hoje pode ser uma área extremamente inovadora e flexível em qualquer negócio, sem intenção de frear, impor ou dificultar processos, muito pelo contrário, é o olhar que corre juntamente com a inovação para garantir a sustentabilidade do que conquistamos até aqui e a segurança das coisas incríveis que ainda lançaremos [7]. 
Por oportuno, o autor traz o seguinte comentário que justifica a importância e a forma de se ter inovação através da sistematização e formalização de um processo de compliance dentro de uma organização da seguinte forma:

\begin{abstract}
[...] as inovações na área de compliance, não focamos mais em executar processos de remediação "quadrados", estamos nos ligando a ferramentas e alertas simplificados para mitigação de riscos, desenvolvendo processos simples e eficazes, colaborando de forma eficiente com adequações para qualquer área da empresa. Não "engessa", não aborrece e ainda transforma todos os envolvidos em gestores que conhecem os riscos a que estão expostos, munidos com ferramentas e controles rápidos e efetivos, indo direto ao ponto, sem delongas desnecessárias, mas aplicar seu tempo no que é realmente importante para o negócio [7].
\end{abstract}

Por fim, diante de uma reflexão ponderada, constata-se que objetivo de uma área de compliance inovadora é ser parceira, antenada com o que está acontecendo no mercado globalizado, compreende as melhores práticas e as aplica ao que está acontecendo dentro do ambiente empresarial, buscando com isso falar uma linguagem de negócio sem incorrer em modelos burocráticos, ou seja, impactando no estratégico sem perder o foco na missão da organização [7].

Diante disso, este estudo pretende analisar se a função do compliance interfere no âmbito das empresas privadas, os pontos positivos e negativos relacionados à inovação, identificando ainda possíveis lacunas no campo de pesquisas.

\title{
2. METODOLOGIA
}

Realizou-se uma revisão sistemática da literatura. A estratégia utilizada de início foi buscar trabalhos concernentes ao tema no repositório científico Web of Science, obedecendo uma sequência de ações: utilizou-se o recurso de busca avançada de seleção de artigos em todos os idiomas no período dos últimos cinco anos, com o primeiro tópico: (Compliance AND Innovation). Por meio da leitura do título e do resumo, no primeiro momento foi identificado 575 documentos. Em um segundo momento a busca no tópico (Governance AND Compliance AND Innovation) identificou-se 52 documentos. No terceiro momento, após realizar a filtragem de trabalhos e leitura de título e resumo, buscando refinamento da amostra por meio da identificação de trabalhos associados com a temática ou que respondiam parcial ou totalmente a seguinte pergunta norteadora relacionada: compliance é um fator inibidor ou determinante para se fomentar inovação?

Dito isso, o período considerado para o estado da arte foram os últimos cinco anos e o ano corrente (de 2015 a 2019). Dai os critérios de seleção seguiram esta ordem:

- Descritores contidos nos títulos, resumos e ou palavras chaves;

- Títulos e resumos concernentes a temática;

- $\quad$ Acesso ao documento completo (visualização e download). 


\section{RESULTADOS E DISCUSSÃO}

As buscas foram realizadas no dia 15 de julho de 2019. Na Tabela 1, pode-se observar o número de publicações encontradas na primeira busca. Já a Figura 1 apresenta os resultados após inclusão da palavra governance considerando que os 52 itens estevam disponíveis para leitura, sendo que foi direcionado para o titulo e o resumo.

Tabela 1. Primeira rodada

\begin{tabular}{ccccccc}
\hline \multirow{2}{*}{ Repositório } & Anos & Ano & Ano & Ano & Ano & \multirow{2}{*}{ Total } \\
\hline Web of Science & $2019^{*}$ & $2018^{*}$ & $2017^{*}$ & $2016^{*}$ & $2015^{*}$ & \\
\hline
\end{tabular}

*Não foram realizadas as estratificações dos trabalhos por ano nesta etapa.

Figura 1. Gráfico da Segunda rodada

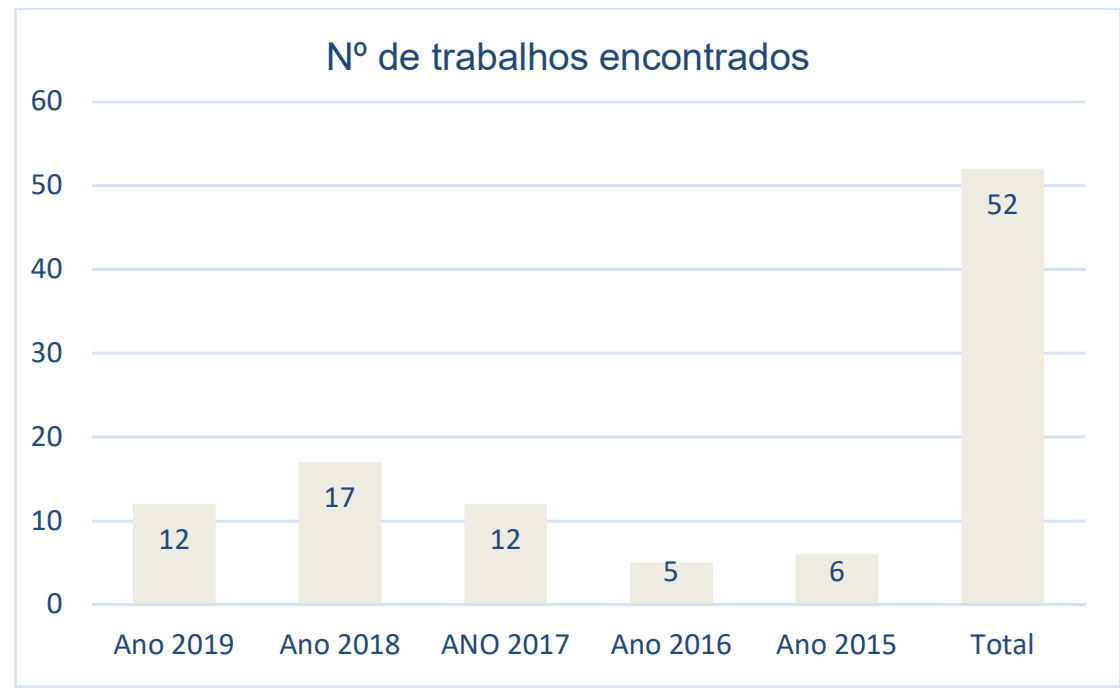

$\mathrm{Na}$ Tabela 2, referente a terceira rodada, observa-se que dos 52 trabalhos encontrados e disponíveis para leitura, apenas um trabalho tinha correlação direta com a proposta de pesquisa sendo que os demais abordavam a temática do compliance principalmente voltados para as áreas especificas de saúde dentre outras.

Tabela 2: Terceira rodada - após leitura do título e resumo

\begin{tabular}{ccccccc}
\hline \multirow{2}{*}{ Repositório } & Ano & Ano & Ano & Ano & Ano & \multirow{2}{*}{ Total } \\
& 2019 & 2018 & 2017 & 2016 & 2015 & (2017 \\
\hline \multirow{2}{*}{ Web of Science } & 01 & - & - & - & - & \multirow{2}{*}{01} \\
\hline
\end{tabular}


$\mathrm{Na}$ Tabela 3, referente a quarta rodada, pode-se identificar que apenas um trabalho respondeu à pergunta central da pesquisa, conforme demonstrado abaixo.

Tabela 3: Quarta rodada

\begin{tabular}{cccccc}
\hline Repositório & Ano & Título & Pergunta & $\begin{array}{c}\text { Resposta } \\
\text { Total }\end{array}$ & $\begin{array}{c}\text { Resposta } \\
\text { Parcial }\end{array}$ \\
\hline $\begin{array}{c}\text { Web of } \\
\text { Science }\end{array}$ & 2019 & $\begin{array}{c}\text { Compliance-innovation: } \\
\text { quality-based route to } \\
\text { sustainability }\end{array}$ & $\mathrm{x}$ & - & $\mathrm{x}$ \\
\hline
\end{tabular}

Como resultado positivo mais relevante do estudo, foi observado que, para alcançar um desempenho de inovação corporativa consistente e forte, a governança e o compliance são relevantes como forma de influenciar decisões, alocar recursos e exercer o controle organizacional, convergindo com o proposito e missão da empresa [3].

Em relação aos fatores negativos, o que mais se destaca é a inexistência de investigações sobre a relação entre governança, compliance e gestão da inovação. Dessa forma, acaba-se por ignorar implicitamente, ou explicitamente, o potencial positivo de influencia que a governança e que o compliance podem exercer nos processos de inovação de uma empresa. Em decorrência disso, os estudos relevam que muitas vezes oportunidades para o crescimento da empresa podem ser negligenciadas por parte da sua gestão. [3].

Por fim, pode-se concluir que a relação entre governança e compliance, por um lado, e inovação, por outro, é ainda pouco debatida na literatura. Diante dessa constatação, estes autores, reiteram que a força da governança é imprescindível para tal integração. Apresenta-se no estudo a sustentabilidade num contexto amplo em que se baseia na capacidade de uma organização equilibrar as necessidades de curto e longo prazo. Assim uma nova mentalidade é necessária para alterar e ampliar a perspectiva entre governança e compliance acima e além da aversão ao risco para abranger uma visão orientada para oportunidades e competitividades [3].

\section{CONCLUSÃO}

Foi verificado que apenas um trabalho dos 52 selecionados tratava da temática foco deste estudo. Assim, os resultados apresentados mostram a escassez de publicações na temática e reforçam a relevância da pesquisa na área como contribuição para sociedade acadêmica e para o contexto empresarial.

Considerando que esta revisão foi realizada em apenas uma base de dados (web of science), sugere-se a necessidade de estender as buscas a outros repositórios. 
Por fim, este trabalho de pesquisa traz como impacto relevante a possibilidade de avaliar-se com mais profundidade a função de compliance no âmbito das empresas privadas. Assim, os resultados obtidos com este trabalho permitem concluir que a função de compliance perpassa os conceitos de governança, inovação e sustentabilidade, como forma de garantir a conformidade. Dessa forma, torna-se um fator preponderante para a manutenção da sustentabilidade e credibilidade empresarial.

Portanto, esta revisão sistemática da literatura é mais uma contribuição relevante para a temática relativamente pouco explorada pela área acadêmica até então.

\section{REFERÊNCIAS}

${ }^{1}$ COIMBRA, M. A; MANZI, V.A (Orgs.). Manual de compliance: preservando a boa governança e a integridade das organizações. São Paulo, 2010.

${ }^{2}$ CUNHA, M. Saiba como implementar um programa de compliance na empresa. LEC - Legal Ethics Compliance. 14 jun. 2018. Disponível em:<http://www.lecnews.com.br/blog/saiba-como-implementar-um-programa-decompliance-na-empresa/>. Acesso em: 17 jun. 2019

${ }^{3}$ DOYLE, E. et al. Compliance-innovation: A quality-based route to sustainability. Journal of the Cleaner Production Chemical, v. 210, p. 266-275, 2019.

4SAMPAIO, J. A evolução do programa de compliance no Brasil. Valor Investe. 20 jun. 2019. Disponível em: <https://valorinveste.globo.com/blogs/nefin/coluna/aevolucao-dos-programas-de-compliance-no-brasil.ghtml>. Acesso em: 15 jul. 2019.

${ }^{5}$ GIOVANINI, W. Compliance a excelência na prática. São Paulo, 2014.

${ }^{6}$ ASSOCIAÇÃO BRASILEIRA DE BANCOS INTERNACIONAIS (ABBI), 2009. Função de compliance. Disponível em: <http://www.abbi.com.br/>. Acesso em: 19 jul. 2019.

${ }^{7}$ GOMES, J. É possível ter/estar em compliance e inovar. 10 abr. 2018. Disponível em: <https://medium.com/compliance-e-inovação-será/é-poss\%C3\%ADvel-ter-estarem-compliance-e-inovar-77774ed559ed>. Acesso em: 10 jul. 2019. 